\title{
PENGEMBANGAN FILM ANIMASI 3 DIMENSI TUDE THE MOVIE-SEJARAH LAGU MERAH PUTIH
}

\author{
I Gusti Agung Mia Pradita 1), I Made Gede Sunarya 2), I Gede Partha Sindu ${ }^{3)}$ \\ Program Studi Pendidikan Teknik Informatika \\ Universitas Pendidikan Ganesha \\ Singaraja, Indonesia \\ Email : igustiagungmiapradita23@undiksha.ac.id ${ }^{1}$, sunarya@undiksha.ac.id ${ }^{2}$, partha.sindu@undiksha.ac.id ${ }^{3}$
}

\begin{abstract}
Abstrak--- Film Animasi 3 Dimensi Tude The Movie-Sejarah Lagu Merah Putih merupakan film yang menceritakan sejarah Lagu Merah Putih yang diperankan oleh Tude. Tude adalah robot yang cerdas, memiliki imajinasi yang tinggi, dan kreatif. Lagu Merah Putih adalah lagu perjuangan yang diciptakan pada tahun 1950 oleh I Gde Dharna menggunakan Bahasa Bali. Lagu Merah Putih dibuat untuk mengenang peristiwa "Perang Bendera" di Pelabuhan Buleleng. Film Animasi 3 Dimensi Tude The Movie-Sejarah Lagu Merah Putih bertujuan untuk mengimplementasikan pembuatan Film Animasi 3 Dimensi Tude The Movie-Sejarah Lagu Merah Putih dan mengetahui respon masyarakat terhadap hasil akhir Film Animasi 3 Dimensi Tude The Movie-Sejarah Lagu Merah Putih. Film Animasi 3 Dimensi Tude The Movie-Sejarah Lagu Merah Putih menggunakan metode Multimedia Development Life Cycle, yang memiliki 6 tahapan, diantaranya adalah concept, design, material collecting, assembly, testing, dan distribution. Dengan dibuatnya Film Animasi 3 Dimensi Tude The MovieSejarah Lagu Merah Putih, masyarakat diharapkan mampu mengetahui dan mengenal sosok pencipta lagu dan kisah perjuangan dibalik lagu Merah Putih. Beberapa pengujian dilakukan pada film animasi ini diantaranya dari pengujian ahli isi yang mendapat hasil $100 \%$, pengujian ahli media mendapat hasil $100 \%$ dan pengujian respon pengguna mendapat respon $3,33 \%$ sangat positif, $95,00 \%$ positif dan $1,67 \%$ cukup positif sehingga film animasi ini dikatakan dalam katagori sangat baik. Kata Kunci : Sejarah Lagu Merah Putih, Film, Animasi 3 Dimensi
\end{abstract}

Abstract--- Animated 3 Dimensional Film Tude The MovieHistory of Red and White Song is a film that tells the history of the Red and White Song played by Tude. Tude is a smart, imaginative, and creative robot. The song Merah Putih is a struggle song composed in 1950 by I Gde Dharna using Balinese. The song Red and White was made to commemorate the events of "Flag War" at Buleleng Harbor. Animated 3
Dimensional Film Tude The Movie-History of Red and White Song aims to implement the making of 3 Dimensional Animation Film Tude The Movie-History of Lagu Merah Putih and to find out the public's response to the final result of the 3 Dimensional Animation Film Tude The Movie-History of Lagu Merah Putih. Animated 3-Dimensional Film Tude The MovieHistory of Red and White Song uses the Multimedia Development Life Cycle method, which has 6 stages, including concept, design, material collecting, assembly, testing, and distribution. With the creation of the 3 Dimensional Tude The Movie-History of the Red and White Song, the public is expected to be able to know and get to know the figure of the songwriter and the story of the struggle behind the song Merah Putih. Some of the tests carried out on this animated film include content expert testing who got $100 \%$ results, media expert testing got $100 \%$ results and testing user responses got a very positive 3,33\% response, 95,00\% positive and 1,67\% quite positive so that this animated film is said to be in a excellent category.

Keywords: History of Red and White Song, Film, 3 Dimensional Animation

\section{PENDAHULUAN}

Indonesia merupakan suatu negara yang sangat kaya akan keanekaragaman budaya, hal ini dikarenakan Indonesia terdiri dari berbagai suku bangsa dimana masing-masing suku bangsa tersebut memiliki perbedaan dan keunikan baik dari segi bahasa daerah, adat istiadat, dan kebiasaan [1]. Kebudayaan merupakan ciptaan manusia yang berlangsung dalam kehidupan [2]. Memperkenalkan kebudayaan sangat perlu dilakukan sejak dini, agar generasi muda lebih mengenal kebudayaannya sendiri. Untuk memperkenalkan 
e-ISSN: 2685-7006 | p-ISSN: $2252-9063$

Kumpulan Artikel Mahasiswa Pendidikan Teknik Informatika

(KARMAPATI)

Volume 10, Nomor 3, Tahun 2021

\section{KARMAPATI}

kebudayaan dapat dengan memanfaatkan teknologi multimedia yang berkembang, dengan memanfaatkan teknologi multimedia dapat mempermudah dalam penyebaran informasi. Jenis teknologi multimedia yang dapat dibuat untuk memperkenalkan kebudayaan yaitu melalui media film, contohnya film lagu Merah Putih.

Lagu Merah Putih diciptakan pada tahun 1950 oleh seniman asal Sukesada, Buleleng yang bernama I Gde Dharna dengan lirik lagu menggunakan Bahasa Bali. I Gde Dharna membuat lagu tersebut terinspirasi dari sejarah perang bendera dengan Belanda di Pelabuhan Buleleng. Lagu Merah Putih memiliki lirik lagu yang sangat sederhana dan nada yang digunakan tidak terlalu sulit sehingga mudah untuk dihapal dan dinyanyikan. Dibalik kepopuleran lagu Merah Putih banyak masyarakat yang tidak mengetahui sosok pencipta lagu Merah Putih dan kisah perjuangan dibalik lagu tersebut. Hal ini dikarenakan kurangnya media publikasi yang membuat masyarakat mengalami keterbatasan untuk mendapatkan informasi tentang I Gde Dharna dan kisah dibalik lagu Merah Putih. Hal ini dibuktikan dengan penyebaran angket oleh peneliti dengan melibatkan 50 responden, dari hasil penyebaran angket tersebut terdapat 50 orang $(100 \%)$ yang mengenali lagu Merah Putih dan 35 orang (70\%) yang mengenali nama pencipta lagu. Namun hanya terdapat 5 orang (10\%) yang mengenali sosok pencipta lagu dan 5 orang (10\%) yang mengenali kisah perjuangan dibalik lagu Merah Putih. Dengan kurangnya media publikasi membuat masyarakat mengalami keterbatasan guna menentukan informasi tentang I Gde Dharna dan kisah dibalik lagu Merah Putih. Berkaitan dengan itu diperlukan media publikasi yang tepat guna memperkenalkan sosok I Gde Dharna dan kisah dibalik lagu Merah Putih. Berdasarkan hasil penyebaran angket terdapat 50 orang (100\%) memilih media elektronik sebagai media publikasi. Selain media, bisa juga dengan memanfaatkan teknologi. Teknologi yang bisa dimanfaatkan adalah mengembangkan sebuah film animasi 3 dimensi tude the movie yang menceritakan Sejarah lagu Merah Putih. Berdasarkan hasil wawancara dengan narasumber dan penyebaran angket dengan melibatkan 50 responden, mendapatkan hasil sebanyak 48 orang (96\%) memilih media film sebagai media publikasi guna memperkenalkan sosok I Gde Dharna dan kisah dibalik lagu Merah Putih serta sebanyak 45 orang (90\%) memilih media film animasi.

Penyampaian informasi melalui media film tentang Sejarah lagu Merah Putih dan kisah dibalik lagu tersebut sudah pernah dibuat oleh (Purnaya, 2019) yang berjudul "Film Dokumenter I Gde Dharna Kisah Heroik Dibalik Lagu Merah Putih. Film tersebut menjadi rujukan guna melakukan perluasan ke dalam bentuk film animasi 3D. Adapun kekurangan dari "Film Dokumenter I Gde Dharna Kisah Heroik Dibalik Lagu Merah Putih yaitu kualitas audio yang masih relatif kurang jelas dan teknik sudut pengambilan gambar masih monoton dan masih terpaku didalam gaya film dokumenter pada umumnya. Film animasi 3D Tude The Movie Sejarah Lagu Merah Putih mempunyai alur cerita yang berbeda dengan film dokumenter yang sudah ada, di mana didalam film animasi 3D ini dikemas ke dalam film bergenre musikal dan perang. Di mana kisah ceritanya diperankan oleh Tude maskot khas dari program studi Pendidikan Teknik informatika, sehingga diharapkan lebih menarik minat masyarakat guna menonton film animasi. Media film animasi 3D sudah pernah dilaksanakan oleh peneliti lain, dengan mendapatkan respon sangat baik dari masyarakat. Salah satu penelitian Film Animasi 3D "Tude The Movie" - Petualangan Si Rina (Tertangkapnya Burung Jalak Bali) (Antara, I Made Yoga; Crisnapati, Padma Nyoman; Wirawan, I Made Agus; Sunarya, 2018), penelitian Film Seri Animasi 3D "Belajar Bahasa Indonesia Bersama Made" Sebagai Media Pembelajaran Bahasa Indonesia Guna Penutur Asing Di Undiksha (Pura, I Putu Andika Subagya; Darmawiguna, I Gede Mahendra; Putrama, 2017) dan Perluasan Film Animasi 3D Kehidupan Didalam Zaman PraSejarah (Pratiwi, Putu Yudia; Darmawiguna, I Gede Mahendra; Sunarya, 2016). Berdasarkan penelitianpenelitian tersebut bisa diperluaksan kedalam film animasi 3D Tude The Movie-Sejarah Lagu Merah Putih. Film animasi 3D Tude The Movie-Sejarah Lagu Merah Putih bisa memvisualkan sosok pencipta lagu dan kisah perjuangan dibalik lagu Merah Putih yang nantinya bisa memberikan informasi kedalam masyarakat, agar masyarakat mengenali sosok pencipta dan kisah perjuangan dibalik lagu tersebut. Melalui film 3D tersebut diharap mampu menyumbangkan bayangan terbarukan kedalam masyarakat guna lebih mengenal Sejarah perjuangan dan mengenal sosok penciptanya. 
e-ISSN: 2685-7006 | p-ISSN: $2252-9063$

Kumpulan Artikel Mahasiswa Pendidikan Teknik Informatika

(KARMAPATI)

Volume 10, Nomor 3, Tahun 2021

\section{KARMAPATI}

Berdasarkan berbagai studi yang berkaitan dengan film animasi 3D dengan itu penulis terdorong untuk mengembangkan film animasi 3D Tude The MovieSejarah Lagu Merah Putih.

\section{KAJIAN TEORI}

A. Sejarah Lagu Merah Putih

I Gde Dharna lahir pada tanggal 27 Oktober 1931 dari pasangan Nyoman Gede dengan Ni Nyoman Rai, sejak kecil beliau sudah menggemari seni musik. Darah seni yang dimiliki beliau mengalir dari sang ibu yang merupakan penyanyi karawitan. Selain mahir dalam bidang seni musik, I Gde Dharna juga masir dalamsastra. Banyak karya-karya besar yang sudah Beliauciptakan seperti lagu Merah Putih, "Taman Pujaan Bangsa Margarana", "Pahlawan Nasional I Gusti Ngurah Rai", "Pewaris Kemerdekaan", "Yuda Mandala Tama", "Bhuana Kerta", "Kembang Jagat", "Tugu Perjuangan Tanah Aron", "Margarana", dan "Gita Pahlawan". Selain lagu, Beliau juga menulis Kumpulan Puisi Bali Modern berjudul "Denpasar Lan Don Pasar", Kumpulan Puisi Delapan Penyair Buleleng berjudul "Pantai Pantai", Kumpulan Drama dan Puisi Bahasa Bali berjudul "Kobarang Apine"[3]. Melalui karyanya Beliau mendapatkan banyak penghargaan bergengsi seperti "Dharma Kusuma" "Rancage", "Widia Pataka", "Wijaya Kusuma" [4]. Selain seorang seniman dan sastrawan, I Gde Dharna juga merupakan seorang veteran. Hal ini dibuktikan dengan tercantumnya nama Beliau sebagai Veteran Pejuang Kemerdekaan Republik Indonesia, dalam Petikan Surat Keputusan Departemen Pertahanan Keamanan tahun 1993.

Pada tahun 1950 I Gde Dharna menciptakan sebuah lagu menggunakan Bahasa Bali dengan judul Merah Putih. Lagu Merah Putih dibuat untuk mengenang peristiwa "Perang Bendera" yang terjadi di Eks Pelabuhan Buleleng pada tanggal 27 Oktober 1945. Peristiwa tersebut membuat gugur salah satu perjuang asal Banjar Liligundi bernama Ketut Merta. Peristiwa "Perang Bendera" membuat I Gde Dharna sedih lalu terinspirasi untuk menciptakan lagu Merah Putih dan membuat lencana merah putih untuk dibagikan kepada para pejuang. Hal ini diceritakan singkat oleh I Gde Dharna dalam bukunya yang berjudul "Dasa Tali Dogen" pada bagian Indik Pengawi. Beberapa sekolah di
Bali kerap menjadikan lagu ini sebagai lagu wajib ketiga yang harus dihapal oleh anak Sekolah Dasar. Lagu pertama adalah Lagu Kebangsaan Indonesia Raya, lagu kedua adalah Hari Merdeka dan lagu ketiga adalah Merah Putih ciptaan mendiang I Gde Dharna (Prasetya, 2017) [5].

\section{B. Film}

Film adalah gambar bergerak, atau sering disebut movie. Menurut undang undang No. 33 Tahun 2009 tentang perfilman [6], film adalah karya seni budaya yang merupakan pranata sosial dan media komunikasi massa yang dibuat berdasarkan kaidah sinematografi dengan atau tanpa suara dan dapat di pertunjukan.

\section{Jenis-jenis Film}

Marcel Danesi dalam buku Semiotik Media, menuliskan terdapat tiga jenis atau kategori utama film, yaitu film fitur, film dokumenter, dan film animasi.

a. Pengertian Film Animasi

Film animasi berasal dari dua ilmu diantaranya film yang berakar pada dunia fotografi dan animasi yang berakar pada dunia gambar.

b. Manfaat Film Animasi

- Melengkapi pengalaman-pengalaman dasar

- Memancing inspirasi baru

- Menarik perhatian

- Penyajian lebih baik karena mengandung nilai-nilai rekreasi

c. Kelebihan Film Animasi

- Film dan video yang mengandung nilai-nilai positif dapat mengandung pemikiran dan pembahasan dalam kelompok anak.

- Film dan video dapat ditunjukan kepada kelompok besar, kecil, maupun perorangan.

d. Kekurangan Film Animasi

- Pengadaan film dan video umumnya memerlukan waktu dan biaya yang mahal.

- Pada saat animasi dipertunjukan, gambar-gambar bergerak terus 
e-ISSN: 2685-7006 | p-ISSN: 2252-9063

Kumpulan Artikel Mahasiswa Pendidikan Teknik Informatika

(KARMAPATI)

Volume 10, Nomor 3, Tahun 2021

KARMAPATI

sehingga tidak semua anak mampu mengikuti informasi yang disampaikan.

Pada film animasi 3 Dimensi Tude The MovieSejarah Lagu Merah Putih menggunakan 2 genre film yaitu genre epic sejarah dan genre musikal.

1. Genre Epic Sejarah umumnya bertema periode masa silam (sejarah) dengan latar cerita sebuah kerajaan, peristiwa atau tokoh besar yang menjadi mitos, legenda atau kisah biblikal.

2. Genre Musikal merupakan kombinasi dari unsur musik, lagu, tarian dan keografi yang menyatu dalam cerita.

D. Animasi

a. Pengertian Animasi

Animasi adalah suatu teknik untuk membuat suatu karya audio visual untuk menghasilkanurutan gambar yang membentuk satu adegan. Animasi merupakan serangkaian gambar gerakcepat yang countine atau terusmenerus yang memiliki hubungan satu dengan lainnya.

b. Jenis-jenis Animasi

Animasi telah berkembang sesuai dengan kemajuan teknologi yang ada sehingga muncul jenis-jenis animasi. Teknik yang digunakan untuk membuat animasi semakin beragam [7]. Jenis-jenis animasi yang sering diproduksi.

* Animasi 2D

* Animasi 3D

* Animasi Stop Motion

c. Prinsip Animasi

Ada berbagai macam - macam teori dan pendapat tentang bagaimana seharusnya animasi itu dibuat. Tetapi setidaknya ada 12 prinsip yang harus dipenuhi untuk membuat sebuah animasi yang hidup. Ke -12 prinsip ini meliputi dasar-dasar gerak, pengaturan waktu, pengkayaan visual, sekaligus teknis pembuatan sebuah animasi.

1. Solid Drawing

2. Timing \& Sacing

3. Squash \& stretch

4. Anticipation
5. Slow In \& Slow Out

6. Arcs

7. Secondary Action

8. Follow Though \& Overlapping Action

9. Straight Ahead Action \& Pose To Pose

10. Staging

11. Appeal

12. Exaggeration

d. Perangkat Lunak

1. Blender

Blender adalah software untuk menggambar animasi 3 dimensi dan sekaligus dapat membuat menjadi sebuah animasi yang memiliki beberapa kelebihan yaitu ukurannya yang relatif kecil dan gratis karena tidak memerlukan registrasi untuk menjalankan softwaretersebut [8].

2. Makehuman

Makehuman merupakan software yang dirancang untuk pembuatan virtual human dengan memanfaatkan Graphical User Interface (GUI). Kegunaan utama dari makehuman adalah menghasilkan virtual human yang realistis secara cepat hanya dengan beberapa klik pada mouse, serta dapat melakukan render dan export untukdigunakan pada project lain [9].

3. Adobe Audition CS6

Adobe Audition adalah aplikasi multimedia untuk mengolah file audio. Aplikasi ini khusus digunakan untukmembantu pengguna komputer yang inginmengolah dan membuat komposisi audio dengan cepat.

4. Adobe Premiere Pro CS6

Adobe Premiere Pro adalah sebuah program penyunting video berbasis non- linear editor (NLE) dari adobe system. Adobe Premiere Pro merupakan salah satu produk software dari Adobe Creative Suite. Adobe Premiere Pro merupakan program pengelolah video.

\section{Adobe Affter Effect CS6}

Adobe After Effect adalah sebuah perangkat lunak yang sangat profesional untuk kebutuhan motion graphic design. 


\section{KARMAPATI}

Perpaduan dari bermacam-macam perangkat lunak, Adobe After Effect menjadi populer dan telah digunakan secara luas dalam pembuatan video multimedia, film, dan website.

E. Animasi 3 Dimensi

Animasi 3D adalah animasi yang dibuat berdasarkan sumbu x, y, dan z, dan objek dapat dilihat dari berbagai sudut pandang. Animasi 3D pada umumnya dikerjakan melalui komputer dan sudah berupa file digital. Animasi 3D merupakan sebuah model yang mempunyai bentuk, volume, dan ruang sehingga dapat dilihat dari segala arah. Secara garis besar proses 3D animasi bisa dibagi 5 tahap yaitu:

1. Modelling

2. Texturing

3. Animating

4. Rigging \& Skinning

5. Rendering

\section{METODOLOGI}

A. Jenis Penelitian

Penelitian ini merupakan jenis penelitian pengembangan Research and Development $(R \& D)$ atau metode penelitian dan pengembangan. Research and Development $(R \& D)$ adalah metode penelitian yang digunakan untuk menghasilkan produk tertentu, dan menguji keefektifan produk. Penelitian ini memiliki tujuan untuk mengembangkan sebuah Film Animasi 3 Dimesi "Tude The Movie-Sejarah Lagu Merah Putih [10].

\section{B. Metode Penelitian}

Penelitian Pegembangan Film Animasi 3 Dimensi "Tude The Movie-Sejarah Lagu Merah Puth menggunakan motede MDLC (Multimedia Development Life Cycle). Metode pengembangan dalam MDLC terdiri dari 6 tahapan, yaitu concept, design, material collecting, assembly, testing, distribution. Seperti gambar dibawah ini.
Volume 10, Nomor 3, Tahun 2021

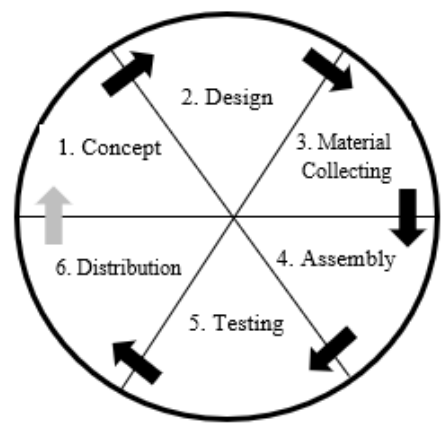

Gambar 2. Tahapan Metode MDLC

\section{Perancangan Film Animasi}

Proses yang dilakukan dalam pembuatan film animasi 3 dimensi Tude The Movie-Sejarah lagu Merah Putih menggunakan tahapan-tahapan dalam pembuatan film dari awal sampai selesai yang terdiri dari proses pra produksi, produksi dan pasca produksi, seperti terlihat pada Gambar 2.

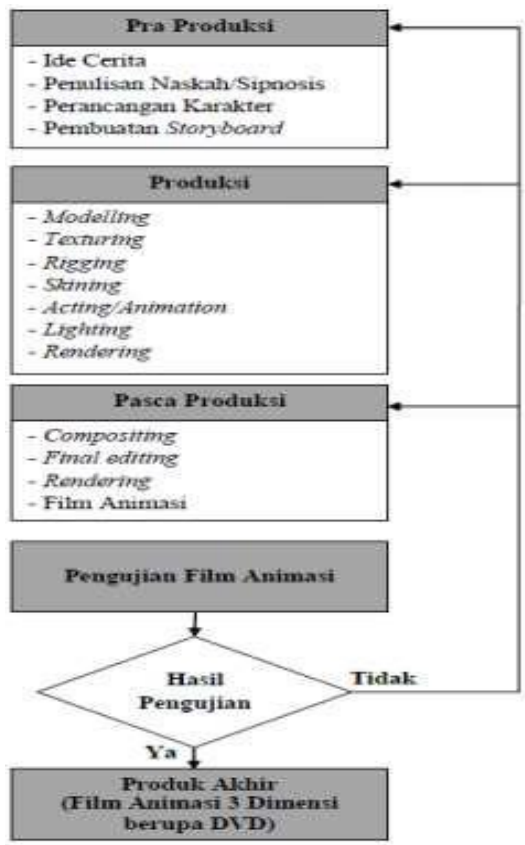

Gambar 2. Proses Pembuatan Film Animasi 3D

\section{Pra Produksi}

Pada tahap Pra Produksi film ini belum dibuat, tetapi persiapan atau perencanaan yang akan diperlukan dalam pembuatan film ini, adapun yang direncanakan sebagai berikut.
- Ide Cerita
- Penulisan Naskah/Sinopsis 
e-ISSN: 2685-7006 | p-ISSN: 2252-9063

Kumpulan Artikel Mahasiswa Pendidikan Teknik Informatika

(KARMAPATI)

Volume 10, Nomor 3, Tahun 2021

KaRmaPaTI

- Perancangan Karakter

Tabel 1. Perancangan Karakter Film Animasi 3D

\begin{tabular}{|l|l|l|}
\hline Nama & Karakter & Karakter \\
\hline 1 & Tude & \\
\hline 2 & Agung & \\
\hline 4 & Ayu & \\
\hline
\end{tabular}

\begin{tabular}{|l|l|l|}
\hline 6 & $\begin{array}{l}\text { Prajurit } \\
\text { Belanda }\end{array}$ & \\
\hline 7 & $\begin{array}{l}\text { Masyara } \\
\text { kat } \\
\text { Buleleng }\end{array}$ & \\
\hline
\end{tabular}

- Perancangan Gambar Pendukung

Tabel 2. Perancangan Gambar Pendukung

\begin{tabular}{|l|l|l|}
\hline No & Nama Gambar & Gambar Pendukung \\
\hline 1 & Rumah Agung & \\
\hline 2 & Kamar Agung & \\
\hline 3 & Ruang Tamu & \\
\hline 5 & Pelabuhan & \\
\hline
\end{tabular}


KARMAPATI

6 Kapal Belanda

E. Produksi

Pada tahap produksi film animasi dibuat sesuai kebutuhan dari pra produksi yang telah dirancang.

1. Modelling

2. Texturing

3. Ringging

4. Skinning

5. Acting/Animatiom

6. Lighting

7. Rendering

F. Pasca Produksi

Pada tahap produksi film animasi dibuat sesuai kebutuhan dari pra produksi yang telah dirancang. Adapun hal yang dilakukan pada tahap produksi adalah sebagai berikut.

- Tahap Perekaman

- Tahap Penggabungan

\section{PEMBAHASAN}

A. Hasil

Pada penelitian ini menghasilakan beberapa hal yang terdiri atas implementasi perangkat lunak dan perangkat keras, implementasi pra produksi, implementasi produksi dan implementasi pasca produksi.

1. Lingkungan Implementasi Film Animasi

a. Spesifikasi Perangkat Keras

Perangkat keras (hardware) yang diperlukan untuk menampilkan Film Animasi 3 Dimensi Tude The Movie-Sejarah Lagu Merah Putih dengan kualitas maksimal adalah perangkat keras yang mendukung dengan video resolusi HD (1280 pixel $\mathrm{x} 720$ pixel). Peralatan yang digunakan dalam pembuatan Film
e-ISSN: 2685-7006 | p-ISSN: 2252-9063

Kumpulan Artikel Mahasiswa Pendidikan Teknik Informatika

(KARMAPATI)

Volume 10, Nomor 3, Tahun 2021

Animasi 3 Dimensi Tude The Movie-Sejarah

Lagu Merah Putih sebagai berikut:

1 buah laptop dengan spesifikasi

$>$ Processor AMD Ryzen 5 3550H with Radeon Vega Mobile Gfx $2.10 \mathrm{GHz}$

$>$ Memory (RAM) $8.00 \mathrm{~GB}$ (7.81 GB usable)

$>$ Type 64-bit Operating System, x64 based processor

$>500 \mathrm{~GB}$ HDD

b. Spesifikasi Perangkat Lunak

Dalam pembuatan Film Animasi 3 Dimensi Tude The Movie-Sejarah Lagu Merah Putih adapun perangkat lunak (Software) yang digunakan untuk dapat menghasilkan film yang maksimal diantaranya:

1. Blender

2. Makehuman

3. Mixamo

4. Adobe Audition CS6

5. Adobe Premiere Pro CS6

6. Adobe Affter Effects

2. Implementasi Pra Produksi

Pada tahap implementasi pra produksi akan dipaparkan mengenai implementasi karakter, implementasi gambar pendukung, dan implementasi storyboard. Tampilan-tampilan dari setiap implementasi film animasi 3 Dimensi Tude The Movie-Sejarah Lagu Merah Putih yaitu sebagai berikut:

- Implementasi Karakter

Tabel 3. Implementasi Karakter

\begin{tabular}{|c|l|c|}
\hline No & Nama Karakter & Karakter \\
\hline 1 & Tude & \\
\hline 2 & Agung & \\
\hline
\end{tabular}


e-ISSN: 2685-7006 | p-ISSN: 2252-9063

Kumpulan Artikel Mahasiswa Pendidikan Teknik Informatika

(KARMAPATI)

Volume 10, Nomor 3, Tahun 2021

KARMAPATI

\begin{tabular}{|l|l|c|}
\hline 3 & Ayu & \\
\hline 4 & Made & \\
\hline 5 & Ayah Agung & \\
\hline 7 & Masyarakat & \\
\hline 6 & Prajurit Belanda & \\
\hline & & \\
\hline
\end{tabular}

- Implementasi Gambar Pendukung

\begin{tabular}{|c|c|c|}
\hline No & Nama Gambar & Gambar Pendukung \\
\hline 1 & Rumah Agung & \\
\hline
\end{tabular}

\begin{tabular}{|c|l|l|}
\hline 2 & Kamar Agung & \\
\hline 3 & Ruang Tamu & \\
\hline 4 & $\begin{array}{l}\text { Pelabuhan } \\
\text { Buleleng }\end{array}$ & \\
\hline 5 & Pantai & \\
\hline 6 & Kapal Belanda & \\
\hline
\end{tabular}

3. Uji Ahli Isi

Uji Ahli Isi dipergunakan untuk mengetahui ketetapan informasi, ketetapan ilustrasi serta kesesuaian isi cerita dengan sinopsis Film Animasi 3 Dimensi Tude The Movie-Sejarah Lagu Merah Putih, instrument uji ahli isi Film Animasi 3 Dimensi Tude The MovieSejarah Lagu Merah Putih dilakukan kepada 2 uji ahli isi yaitu Bapak Putu Oka Sastra, S.P., M.Ma dan Ibu D.ra Desak Made Oka Purnawati, M.Hum. Hasil pada tahap uji validitas ahli isi peneliti mendapat kesesuaian dengan representasi $100 \%$. Untuk rumus pengujian yang digunakan untuk membandingkan antara dua jawaban ahli isi, peneliti menggunakan rumus Uji Gregory, rumus pengujian Gregory sebagai berikut :

Validasi isi $\frac{D}{A+B+C+D}=\frac{5}{5}=1.0$

4. Uji Ahli Media 
e-ISSN: 2685-7006 | p-ISSN: 2252-9063

Kumpulan Artikel Mahasiswa Pendidikan Teknik Informatika

(KARMAPATI)

Volume 10, Nomor 3, Tahun 2021

\section{KARMAPATI}

Uji ahli media dipergunakan untuk mengetahui kesesuaian visual, kesesuaian audio dan kesesuaian isi alur cerita pada Film Animasi 3 Dimensi Tude The Movie-Sejarah Lagu Merah Putih. Uji ahli media ini menggunakan 2 ahli penguji media. Penguji ahli media pertama adalah Bapak I Nengah Eka Mertayasa, S.Pd., M.Pd. dan penguji ahli media kedua adalah Bapak I Gede Bendesa Subawa, S.Pd., M.Kom. Hasil dari pengujian ahli media mendapat kesesuaian dengan representasi $100 \%$. Untuk rumus pengujian yang digunakan untuk membandingkan antara dua jawaban ahli media peneliti menggunakan rumus Gregory.

$$
\text { Validasi Media }=\frac{D}{A+B+C+D}=\frac{6}{6}=1.00
$$

\section{Uji Respon pengguna}

Uji Respon Pengguna dilakukan untuk mengetahui kepuasan dan tanggapan masyarakat terhadap Film Animasi 3 Dimensi Tude The Movie-Sejarah Lagu Merah Putih. Metode yang digunakan dalam menghitung respon pengguna menggunakan metode skala likert. Untuk perhitungan uji respon pengguna menggunakan rumus:

$$
X=\frac{\sum x}{\mathrm{~N}}
$$

Film Animasi 3 Dimensi Tude The Movie-Sejarah Lagu Merah Putih mendapatkan hasil data sebanyak 2 orang dengan persentase $3,33 \%$ berkategori sangat positif, 57 orang dengan persentase $95,00 \%$ berkategori Positif, dan sebanyak 1 orang dengan persentase 1,67\% berkategori cukup positif . Tidak ada responden yang masuk ke dalam kategori kurang positif dan kategori sangat kurang positif. Dengan didapatkannya data tersebut maka Film Animasi 3 Dimensi Tude The MovieSejarah Lagu Merah Putih dikatakan mendapat respon positif dikalangan masyarakat Buleleng.

\section{B. Pembahasan}

Pengembangan Film Animasi 3 Dimensi Tude The Movie-Sejarah Lagu Merah Putih ini bertujuan untuk memberikan visualisasi tentang cerita dibalik lagu Merah Putih dan sosok dari pencipta lagu Merah Putih. Lagu Merah Putih merupakan lagu yang sangat populer dikalangan masyarakat, tetapi banyak masyarakat yang tidak mengetahui bagaimana kisah dibalik lagu dan sosok pencipta lagu merah putih. Pengembangan Film Animasi 3 Dimensi Tude The Movie-Sejarah Lagu
Merah Putih menggunakan metode MDLC (Multimedia Development Life Cycle). Metode MDLC memiliki 6 tahapan diantaranya tahapan concept, design, material collecting, assembly, testing dan distribution. Berikut penjelasan peneliti dalam menggunakan 6 tahapan metode MDLC.

Tahap pengonsepan (concept) adalah tahapan pertama yang peneliti lakukan dalam mengembangkan film animasi. Pada tahapan ini peneliti mulai mencari informasi yang berkaitan dengan film animasi dan penetapan konsep awal dari film animasi. Pada tahapan ini dilakukan penentuan film animasi yang akan dibuat kedalam bentuk animasi 3 Dimensi.

Tahap kedua yaitu tahapan perancangan (design) pada tahapan ini peneliti menetapkan sebuah rancangan karakter dari tokoh-tokoh yang terlibat dalam pembuatan film animasi 3 Dimensi dimulai dari tokoh Tude, Agung, Ayu, Made, Ayah Agung, Masyarakat Buleleng, dan Prajurit Belanda. Selain itu, peneliti juga mendesain tempat yang digunakan sebagai background dalam pembuatan setiap scene. Peneliti tidak hanya merancang karakter dan latar tempatnya saja, peneliti juga merancang desain cover CD, DVD dan poster film animasi 3 Dimensi Tude The Movie-Sejarah Lagu Merah Putih.

Tahap ketiga yaitu tahapan pengumpulan bahan (material collecting) pada tahapan ini peneliti mengumpulkan semua bahan yang diperlukan dalam pembuatan film animasi 3 Dimensi. Bahan-bahan yang dikumpulkan berupa dubbing suara karakter, backsound serta hal-hal yang menunjang dalam pembuatan film animasi 3 Dimensi.

Tahap keempat yaitu tahapan pembuatan (assembly) tahapan ini merupakan tahapan pembuatan animasi, tahapan ini dibagi menjadi 2 bagian yaitu tahap produksi dan tahap pasca produksi. Pada tahap produksi dilakukan pembuatan animasi 3 Dimensi dengan langkah yang dilakukan seperti modelling karakter, texturing, rigging, skinning, animating, lighting, yang sudah berhasil peneliti implementasikan dan pada tahap rendering terdapat kendala alat yang digunakan. Untuk tahap pasca produksi hal yang dilakukan adalah mengedit audio dan mengedit video animasi yang sudah selesai dirender pada Blender untuk digabungkan menjadi sebuah film animasi yang utuh. Kemudian penelitian[11] yang mana mempergunakan cara Block Diagram yang terbagi menjadi 3 tahap pemrosesan yakni tahap pra-produksi, tahap produksi dan tahap pasca produksi. Sementara 
e-ISSN: 2685-7006 | p-ISSN: 2252-9063

Kumpulan Artikel Mahasiswa Pendidikan Teknik Informatika

(KARMAPATI)

Volume 10, Nomor 3, Tahun 2021

\section{KARMAPATI}

didalam penelitian yang peneliti lakukan terbagi menjadi 2 tahap yakni tahap produksi dan pasca produksi dan aktivitas pembuatan ide cerita, pembuatan karakter, dan pembuatan storyboard dilaksanakan sebelum pengerjaan animasi yaitu didalam tahap pengonsepan (concept). Selanjutnya penelitian yang dilaksanakan oleh[12] dimana didalam penelitian ini terdapat kekurangan yang dipaparkan menyerupai proses penganimasian yang kurang maksimal, sehingga berpengaruh terhadap hasil film animasi yang masih kaku dan tidak begitu nyata. Didalam penelitian yang peneliti lakukan mendapatkan hasil proses penganimasian yang sudah cukup maksimal, dimana hasil animasi sudah nampak nyata.

Tahap kelima yaitu tahapan pengujian (testing) tahapan ini merupakan tahapan menganalisis film animasi 3 Dimensi yang dibuat berdasaarkan 3 uji diantaranya Uji ahli isi, Uji ahli Media, dan Uji Respon pengguna. Pada uji ahli isi mendapatkan respon sebesar $100 \%$. Hal tersebut mengidentifikasikan bahwa isi cerita dari film animasi yang disampaikan sudah sesuai dengan sumber cerita sejarah Lagu Merah Putih. Pada uji ahli media mendapatkan respon sebesar 100\%. Film animasi disajikan dengan audio dan visual yang cukup menarik dan ditambahkan dengan subtitle, sehingga masyarakat yang menonton dapat dengan mudah memahami cerita yang disampaikan pada film animasi 3 Dimensi Tude The MovieSejarah Lagu Merah Putih.Dari evaluasi ahli media terdapat beberapa saran yang diberikan dan sudah dikerjakan oleh peneliti sebelum melakukan uji respon pengguna. Untuk uji respon pengguna peneliti menggunakan 60 responden secara acak yang merupakan masyarakat asli Buleleng yang tersebar dibeberapa kecamatan yang berada di Buleleng. Reponden masyarakat disebar secara online menggunakan google from dengan jumlah soal sebanyak 10 butir. Adapun hasil respon yang didapat yaitu sebesar $3,33 \%$ masyarakat merespon sangat positif, sebesar $95,00 \%$ masyarakat merespon positif, dan sebesar $1,67 \%$ masyarakat merespon cukup positif. Untuk 3,33\% respon masyarakat dapat dilihat dari segi pertanyaan mengenai makna yang disampaikan pada film animasi 3 Dimensi Tude The Movie-Sejarah Lagu Merah Putih dan responden dapat mengetahui kisah dibalik lagu Merah Putih, untuk 95,00\% respon masyakarat dapat dilihat dari segi pertanyaan alur cerita pada film animasi 3 Dimensi Tude The Movie-Sejarah Lagu Merah Putih, dan 1,67\% respon masyarakat dapat dilihat dari segi pertanyaan ketidak tahuan masyarakat terhadap sosok pencipta lagu Merah Putih. Film animasi 3 Dimensi Tude The MovieSejarah Lagu Merah Putih lebih banyak mendapat respon positif dari masyarakat dikarenakan adanya visualisasi yang menceritakan sosok pencipta dan kisah dibalik lagu Merah Putih. Pada penelitian yang dilakukan oleh [13] Hasil penelitian pada penelitian ini mendapatkan peningkatan dari penelitian sebelumnya, dimana penelitian sebelumnya mendapatkan hasil responden dengan persentase $94,36 \%$ dan didalam penelitian ini mendapatkan hasil responden dengan persentase $95 \%$.

Tahap keenam yaitu tahapan distribusi (distribution) meruapakan tahapan terakhir dalam pembuatan film animasi 3 Dimensi. Tahapan ini adalah tahapan pendistribusian film animasi, film animasi 3 Dimensi Tude The Movie-Sejarah Lagu Merah Putih di distribusikan ke Dinas kebudayaan Kabupaten Buleleng.

Jadi, Film Animasi 3 Dimensi Tude The Movie Sejarah Lagu Merah Putih merupakan film yang dapat menyampaiakan informasi secara nyata kepada penonton melalui animasi yang digunakan pada film sehingga menambah wawasan masyarakat terhadap sosok pencipta lagu dan kisah dibalik lagu Merah Putih. Film Animasi 3 Dimensi Tude The Movie-Sejarah Lagu Merah Putih juga memiliki manfaat untuk memperkenalkan sosok pencipta lagu dan kisah dibalik lagu Merah Putih. Sehingga, masyarakat yang tidak mengetahui sosok dan kisah dibalik lagu Merah Putih menjadi tahu setelah menonton film animasi ini, dan memiliki motivasi untuk terus mempertahankan nilainilai perjuangan.

\section{KESIMPULAN}

Berdasarkan hasil penelitian, pembahasan dan pengujian pada penelitian Pengembangan Film Animasi 3dapat ditarik kesimpulan sebagai berikut :

1. Pengembangan Film Animasi 3D Tude The Movie-Sejarah Lagu Merah Putih yang menceritakan tentang sosok Pencipta lagu dan kisah perjuangan dibalik lagu Merah Putih yang dikemas dalam bentuk film animasi 3D menggunakan software Blender serta softwaresoftware penunjang lainnya seperti Adobe Primere Cs6, Adobe Audition Cs6, Adobe After Effect, dan software lainnya. Dengan adanya Film Animasi 3D Tude The Movie-Sejarah lagu Merah Putih ini agar mampu memberikan informasi dan gambaran tentang sosok pencipta lagu dan kisah dibalik lagu Merah Putih, serta dapat menambah wawasan masyarakat terhadap cerita perjuangan yang pernah terjadi di Kabupaten Buleleng.

2. Respon yang didapatkan dari masyarakat akan Film Animasi 3D Tude The Movie-Sejarah Lagu Merah Putih sebesar 3,33\% masyarakat 
e-ISSN: 2685-7006 | p-ISSN: 2252-9063

Kumpulan Artikel Mahasiswa Pendidikan Teknik Informatika

(KARMAPATI)

Volume 10, Nomor 3, Tahun 2021

KARMAPATI

sangat positif, $95 \%$ masyarakat positif dan sebesar 1,67\% masyarakat cukup positif. Maka dengan respon yang di dapat Film Animasi 3D Tude The Movie-Sejarah Lagu Merah Putih dapat dikategorikan film animasi yang sangat baik.

\section{REFERENSI}

[1] R. Prayogi and E. Danial, "Pergeseran Nilai- Nilai Budaya Pada Suku Bonai Sebagai Civic Culture Di Kecamatan Bonai Darussalam Kabupaten Rokan Hulu Provinsi Riau,"Humanika, vol. 23, no. $\quad 1, \quad 2016$, doi: 10.14710/humanika.v23i1.11764.

[2] H. M. Bahar and A. Teng, "Filsafat KebudayaanDan Sastra (Dalam Perspektif Sejarah)," vol. 5, no. 1, pp. 2354-7294, 2017.

[3] I. M. Sujaya, Begini Kisah Lagu "Merah Putih"Karya Gde Dharna., 2018th ed. www.balisaja.com: http://www.balisaja.com/2015/09/beginikisah- di-balik-lagu-merahputih.html, 2015.

[4] D. B. Dharmawan, D. W., \& Kurniawan, Biografi Sang Veteran dan Seniman I Gde Dharna. Singaraja: SMA Negeri 1 Singaraja,2008.

[5] E. Prasetya, Novel Terakhir yang Hilang -Mengenang 2 Tahun Kepergian Seniman I GdeDharna., 2018th ed.

www.tatkala.co: http://tatkala.co/2017/09/13/novelterakhir- yanghilang-mengenang-2-tahunkepergianseniman-i-gde-dharna/, 2017.

[6] Benedí C. \& Güemes J., "UNDANGUNDANG REPUBLIK INDONESIA,"
Society, vol. 3, p. 464, 2009.

[7] Z. Djalle, The Making 3D Animation Movie.Jakarta: Gramedia, 2007.

[8] H. Cahyaka, Penggunaan Media Animasi 3 Dimensi Berbasis Blender Pada Mata PelajaranKonstruksi Bangunan di Kelas $X$ SMK Negeri 7 Surabaya. Jurnal Kajian Pendidikan Teknik Bangunan, 110-114., 2017.

[9] S. R. U. . Lestaril, Widya Ayu; Sugiarso, Brave A; sompie, "Aplikasi Mobile Learning InteraktifBacaan Doa Sehari-hari dan Dzikir Pagi \& Petang," J. Tek. Inform., vol. 14 , no. 1 , pp. $99-108$, 2019, doi: 10.35793/jti.14.1.2019.23982.

[10] Sugiyono, Metode Penelitian Pendidikan Pendekatan Kuantitatif, Kualitatif, dan $R$ \& D. Bandung: Alfabeta, 2009.

[11] Antara, I Made Yoga; Crisnapati, Padma Nyoman; Wirawan, I Made Agus; Sunarya, I. M. G. (2018). PENGEMBANGAN FILM ANIMASI 3 DIMENSI “ TUDE THE MOVIE PETUALANGAN SI RINA ( TERTANGKAPNYA BURUNG JALAK BALI)." 7, 214-223.

[12] Wardiana, I Nyoman Adi; Piarsa, I Nyoman; Sasmita, G. M. A. (2015). Rancang Bangun Film Animasi 3 Dimensi Sejarah Pura Tanah Lot. E-Journal SPEKTRUM, 2(4), 20-25.

[13] Purnaya, Nyoman Ari; Darmawiguna, I Gede Mahendra; Santyadiputra, G. S. (2019). Film Dokumenter I Gde Dharna "Kisah Heroik Dibalik Lagu Merah Putih." 